\title{
LOGÍSTICA REVERSA - UMA ESTRATÉGIA EMPRESARIAL NECESSÁRIA E COMPENSADORA
}

\section{ARTIGO ORIGINAL}

BUENO, Rodolfo Cesar de Souza Barcellos ${ }^{1}$

OLIVEIRA, Lismari Cunha de ${ }^{2}$

BUENO, Rodolfo Cesar de Souza Barcellos. OLIVEIRA, Lismari Cunha de. Logística reversa - uma estratégia empresarial necessária e compensadora. Revista Científica Multidisciplinar Núcleo do Conhecimento. Ano 04, Ed. 08, Vol. 06, pp. 0518. Agosto de 2019. ISSN: 2448-0959

\section{RESUMO}

O presente artigo explicita a logística reversa como uma estratégia empresarial necessária e compensadora. Tendo como objetivos identificar a logística verde e reversa como operações que preservam o meio ambiente; apresentar a logística reversa como uma área indispensável às empresas e a sociedade e os benefícios resultantes dessa operação. Utilizou-se a pesquisa bibliográfica, por meio de livro e artigos científicos referentes ao tema apresentado. Constatou-se que as empresas dispõem de ferramentas de gestão suficientes para atuar com logística reversa. E ao fazerem isso atenderão a legislação, preservarão o meio ambiente e gozarão de boa reputação junto aos clientes.

1 Pós-graduação em Docência na Educação Profissional e Tecnológica; MBA em Logística e Operações Globais; MBA em Marketing Empresarial; Bacharel em Administração de Empresas.

2 Orientadora; Especialização em andamento em Formação Em Educação A Distância; Especialização em Gestão Financeira E Controladoria; Graduação em Ciências Contábeis. 
Palavras-chave: Estratégia, logística reversa, meio ambiente.

\section{INTRODUÇÃO}

O meio ambiente fornece todos os recursos necessários para a sobrevivência do ser humano, o ar, o alimento, as roupas, moradia e todas as conveniências devidamente apreciadas e necessárias. Entretanto, os homens têm explorado a natureza de maneira descabida, trazendo males para si próprios, suas gerações futuras e para a Terra, após muitas pesquisas e constatações são evidentes a degradação ambiental causada pela sociedade como um todo, em especial pelas indústrias que consomem, produzem e distribuem em grande escala com pouca preocupação com o ciclo de vida do seu produto.

A logística empresarial é a área da gestão que gerencia as atividades de extração das matérias primas, transporte, armazenamento, transformação, distribuição e entrega dos produtos acabados ao consumidor final e a logística reversa cuida exatamente do fluxo oposto, ou seja, gerencia o retorno dos bens dos consumidores para os varejistas, distribuidores e setor produtivo, valendo-se das típicas atividades logísticas de transporte, armazenagem, estoque, movimentação, expedição e recebimento, além dos fluxos de informações e financeiro. O problema, objeto de análise dessa pesquisa é: Por que a maior parte das empresas ainda não olha a logística reversa como uma atividade estratégica?

O objetivo geral desse estudo é explicitar a logística reversa como uma estratégia empresarial necessária e compensadora para as empresas, que, ao operarem suas atividades preocupadas com as questões ambientais serão beneficiadas com boa reputação, amparo legal, e se tornarão mais competitivas e apreciadas por consumidores críticos atentos a preservação do meio ambiente. Além disso, pretendese examinar a logística verde e a logística reversa, identificando como a operação reversa beneficia o meio ambiente; identificar a logística reversa como uma estratégia empresarial competitiva e indispensável para atender a sociedade moderna e revelar 
os benefícios para empresas que atuam com logística reversa, como boa reputação, fidelização dos clientes e diferencial competitivo.

É notório que as empresas ao adotarem a logística reversa como uma estratégia necessária e compensadora colherão bons frutos, pois o assunto sustentabilidade ambiental é sério e importante, com dimensões globais. Foi com a criação da Organização das Nações Unidas (ONU) nos anos 50 que as primeiras iniciativas voltadas para questões ambientais foram tomadas, criando convenções e relatórios internacionais para normatizar, medir e avaliar os impactos negativos que as diversas atividades produtivas causam ao meio ambiente, comprometendo e responsabilizando os países por suas ações poluidoras.

Essa pesquisa é uma oportunidade para as empresas refletirem sobre suas atividades produtivas, identificando formas de amenizar e/ou eliminar ações potencialmente poluidoras, perceberem também que a logística reversa é uma estratégia de negócio necessária e compensadora, pois, ao cuidarem do ciclo de vida dos seus produtos contribuirão efetivamente para diminuir os danos causados ao meio ambiente, sua reputação corporativa fortalecerá e ampliará sua participação no mercado, será bem vista pela sociedade nacional e internacional e valorizada por seus clientes, que hoje estão cada vez mais críticos e atentos às questões ambientais.

Para alcançar os objetivos desse estudo utilizou-se a metodologia de pesquisa exploratória, que segundo Gil (1946, p. 41) "[...] têm como objetivo proporcionar maior familiaridade com o problema, com vistas a torná-lo mais explícito ou a construir hipóteses". Quanto ao procedimento técnico operativo aplicou-se a pesquisa bibliográfica, que conforme Gil (1946, p. 44) "é desenvolvida com base em material já elaborado, constituída principalmente de livros e artigos científicos". Por meio dessas premissas científicas espera-se que esse estudo seja eficiente e proveitoso aos interessados.

O seguinte material será utilizado na concepção do presente trabalho: a apostila de Logística Reversa e Sustentabilidade do MBA em Logística e Operações Globais 
UCAM/RJ; os artigos: "A caracterização da logística reversa no ambiente empresarial em suas áreas de atuação: pós-venda e pós-consumo agregando valor econômico e legal" (autores: Patrícia Guarnieri, Prof. Dr. Ivanir Luiz de Oliveira); "Logística reversa: oportunidades para redução de custos em decorrência da evolução do fator ecológico" (autores: Sueli Ferreira de Souza, Sérgio Ulisses Lage da Fonseca); "Marketing verde como estratégia de sucesso da imagem corporativa" (autores: Eduardo Ferreira Chaves Regina Rianelli de Brito, José Carlos Beker, Jesus Domech Moré) e o livro "Logística Verde" (autor: Vitório Donato).

\section{REFERENCIAL TEÓRICO}

\subsection{LOGÍSTICA VERDE E REVERSA - BENEFÍCIOS CONCRETOS AO MEIO AMBIENTE}

Não é tão clara a distinção entre logística verde e logística reversa, nas obras disponíveis é comum identificá-las como sendo a mesma coisa, entretanto, Donato (2008, p. 15) esclarece que:

A Logística Verde ou Ecologística é a parte da logística que se preocupa com os aspectos e impactos ambientais causados pela atividade logística. Por se tratar de uma ciência em desenvolvimento ainda existe uma grande confusão conceitual a respeito desse conceito.

Nota-se que a logística verde preocupa-se com os aspectos e impactos ambientais causados pela atividade logística, isto é, a poluição do ar por conta queima de combustíveis dos veículos de transportes rodoviários; a poluição marítima causada por alijamento de resíduos (derramamento de óleo cru e derivados do petróleo no mar); vazamentos de resíduos industriais causados pelo armazenamento inadequado; interferência no habitat natural, atropelamentos de animais nativos e ruídos intensos que interferem no ciclo de vida de algumas espécies ao implantar uma infraestrutura de logística. Esses são alguns aspectos e impactos ambientais causados por algumas atividades logísticas, que não se esgotam nesses exemplos. 
E o que é logística reversa? Segundo Donato (2008, p. 19):

O processo de logística reversa movimenta materiais reaproveitados que retornam ao processo tradicional de suprimento, produção e distribuição. A logística reversa é composta por série uma de atividades que a empresa tem que realizar para atendê-la, como por exemplo, coletas, embalagens, separações, expedição até os locais de reprocessamento dos materiais quando necessário.

Identifica-se que a logística reversa, necessariamente, opera o retorno dos materiais às atividades logísticas tradicionais, tais como suprimentos, produção e distribuição, ou seja, existe uma preocupação específica em estruturar um fluxo logístico reverso para dar conta do reaproveitamento dos materiais utilizados. Observa-se que enquanto a logística verde avalia tão somente o impacto ambiental de uma atividade logística, a logística reversa está preocupada em retornar produtos utilizados aos centros produtivos para serem reaproveitados.

Logística verde e reversa assemelha-se no sentido de que, quando aplicadas, geram importantes ganhos ambientais e difere-se em suas operações, pois, enquanto numa procura-se controlar a atividade logística para não causar/minimizar impacto ambiental, na outra se procura estruturar um canal logístico reverso para retornar seus produtos acabados, a fim de reaproveita-los ou descarta-los corretamente.

A fim de obter um melhor entendimento de como a logística reversa agrega valor ecológico é oportuno expressar algumas conceituações. De acordo com Lacerda (apud Souza e Fonseca, 2009, p. 31):

Logística reversa pode ser entendida como sendo o processo de planejamento, implementação e controle do fluxo de matérias-primas, estoque em processo, e produtos acabados (e seu fluxo de informação) do ponto de consumo até o ponto de origem, com o objetivo de recapturar valor ou realizar um descarte adequado. 
Verifica-se como característica principal da logística reversa, o gerenciamento das atividades logísticas do ponto de consumo até o ponto de origem, com o objetivo de recuperar valor dos produtos acabados de diversas formas: econômico, ecológico, legal, entre outros. Além disso, o descarte adequado do produto, após sua utilização é essencial para caracterizar a logística reversa como ferramenta eficaz na preservação ambiental.

Outro conceito importante é a divisão da logística reversa em operações distintas, segundo (Guarnieri e Oliveira, 2005, p.124):

A logística reversa pode ser dividida em duas áreas de atuação: logística reversa de pós-venda e logística reversa de pós-consumo. A primeira pode ser entendida como a área da logística reversa que trata do planejamento, do controle e da destinação dos bens sem uso ou com pouco uso que retornam à cadeia de distribuição por diversos motivos: devoluções por problemas de garantia, avarias no transporte, excesso de estoques, prazo de validade expirado, entre outros. Já a logística reversa de pós-consumo pode ser vista como a área da logística reversa que trata dos bens no final de sua vida útil, dos bens usados com possibilidades de reutilização (embalagens) e os resíduos industriais.

Identificada às duas áreas de atuação da logística reversa, conclui-se que a logística de pós-venda tem pouco ou quase nenhum ganho ambiental, pois o produto foi pouco usado e em alguns casos nem foi usado, por isso não é descartado pelo consumidor final e sim devolvido aos canais de distribuição reversos, já a logística de pós-consumo pode gerar ganhos ambientais significativos.

Leite (2003, apud Guarnieri e Oliveira, 2005, p.125), afirma que em algum momento os bens produzidos serão de pós-consumo, portanto é necessário que se viabilizem meios controlados para o descarte desses bens no meio ambiente, então, qual é a melhor forma de descartar esses produtos? De acordo com a Política Nacional de Resíduos Sólidos (PNRS, 2010) artigo 9: 
Na gestão e gerenciamento de resíduos sólidos, deve ser observada a seguinte ordem de prioridade: não geração, redução, reutilização, reciclagem, tratamento dos resíduos sólidos e disposição final ambientalmente adequada dos rejeitos.

Seguindo essa ordem de descartabilidade a logística de pós-consumo agrega valor ambiental e econômico, pois se aproveita ao máximo a utilização do bem, antes que se torne um rejeito para ser incinerado ou depositado em aterros sanitários (medidas controladas) e ao inserir esse bem novamente ao setor produtivo como insumo, por meio da reciclagem, gera valor econômico ao substituir a compra de novas matérias primas, geralmente oriundas de exploração ambiental.

A atividade de reciclagem na logística de pós-consumo contribui significativamente com o meio ambiente, pois ao diminuir a quantidade de lixo descartado protege-se o solo, o ar e água. Além de diminuir a necessidade de explorar matérias primas nos recursos naturais, pois o material reciclado passa a ser utilizado como insumo necessário à produção. De acordo com Suçuarana:

Na reciclagem do vidro o aproveitamento da matéria prima é de $100 \%$, ou seja, para cada tonelada de caco de vidro, obtém-se uma tonelada de vidro novo. Quanto ao papel, a matéria prima mais utilizada na sua fabricação é a madeira. Quase todo tipo de papel pode ser reciclado e a reciclagem de cerca de $50 \mathrm{~kg}$ de papel evita o corte de uma árvore para a produção da mesma quantidade.

O metal é um material de elevada durabilidade e sua reciclagem evita as despesas da fase de redução do minério a metal, que é uma fase com alto consumo de energia. [...] A matéria prima usada na fabricação do plástico é a resina sintética derivada do petróleo. Assim, a cada 100 toneladas de plástico reciclado economiza-se uma tonelada de petróleo.

Além do vidro, papel, metal e plástico, outros materiais como borrachas, baterias e pilhas podem ser reciclados, favorecendo sobremaneira o meio ambiente. 


\subsection{LOGÍSTICA REVERSA - UMA ESTRATÉGIA EMPRESARIAL COMPETITIVA E INDISPENSÁVEL PARA ATENDER A SOCIEDADE MODERNA}

Ao definirem suas estratégias para competirem no mercado às empresas utilizam importantes ferramentas de gestão, uma delas é a Análise ambiental, que representa o macro e o micro ambiente de negócios em que as organizações estão envolvidas. Isso fornece a empresa uma visão geral do seu contexto de negócios, servindo de insumo básico para que a mesma realize o seu planejamento estratégico e defina suas metas para competir no mercado. A figura abaixo ilustra esse ambiente.

Figura 1 - A empresa, o ambiente geral e o ambiente de tarefa.



Fonte: Interpretando o Aprender

O círculo vermelho denominado ambiente da tarefa, representa o ambiente peculiar de cada empresa e suas variáveis, o circulo verde denominado ambiente geral representa o contexto comum a todas as empresas e suas variáveis. Dentre todas 
essas variáveis, três, são particularmente importantes para esse estudo, o cliente e as variáveis ecológicas e legais.

No que tange a percepção do cliente sobre a empresa que pratica logística reversa, Barreto (s/ano) sinaliza que:

Os varejistas acreditam que os clientes valorizam as empresas que possuem políticas mais liberais de retorno de produtos. Essa é uma vantagem percebida na qual os fornecedores e varejistas assumem os riscos pela existência de produtos danificados. Isso envolve, é claro, uma estrutura para recebimento, classificação e expedição de produtos retornados.

No entanto para que essa percepção se concretize a ponto de fidelizar o cliente, é necessário que a empresa estruture sua operação de logística reversa, tratando-a de forma sistemática e contínua e não como casos esporádicos aos seus negócios. A tabela abaixo demonstra como a empresa pode estruturar sua operação de logística reversa.

Tabela 1 - Fatores críticos para eficiência do processo de logística reversa

\begin{tabular}{|lr|l|l|}
\hline $\begin{array}{l}\text { Bons Controles de } \\
\text { Entrada }\end{array}$ & $\begin{array}{l}\text { Processos Mapeados e } \\
\text { Formalizados }\end{array}$ & Ciclo de Tempo Reduzido \\
\hline $\begin{array}{l}\text { Sistemas } \\
\text { Informação }\end{array}$ & de & Rede Logística & Relações Colaborativas entre \\
Acurados & Planejada & Clientes e Fornecedores \\
\hline
\end{tabular}

Fonte: Barreto (s/ano)

Conforme Barreto (s/ano) Bons controles de entrada - identificar corretamente o estado dos materiais que retornam para que estes possam seguir o fluxo reverso correto; Processos mapeados e formalizados - tratar a logística reversa como uma atividade regular e não esporádica; Tempo de ciclo reduzidos - se refere ao tempo 
entre a identificação da necessidade de reciclagem, disposição ou retorno de produtos e seu efetivo processamento; Sistema de informação - capacidade de rastreamento de retornos, medição dos tempos de ciclo, medição do desempenho dos fornecedores; Rede logística planejada - ligar de forma eficiente os pontos de consumo onde os materiais usados devem ser coletados até as instalações onde serão utilizados no futuro. Relações colaborativas entre clientes e fornecedores buscarem entendimento mútuo sobre possíveis produtos danificados no transporte ou mau planejamento de manuseio e armazenagem.

Por meio dessa estrutura de logística reversa as empresas atenderão as expectativas dos clientes do ponto de vista comercial e ecológico, pois os mesmos terão condições de retornar produtos que não atenderam suas necessidades e também perceberão com bons olhos as organizações que disponibilizaram um sistema racional de coleta e tratamento de produtos já utilizados. Muitas vezes o cliente, cônscio da sua responsabilidade ambiental sente-se incomodado por não saber como descartar um produto após sua vida útil, e guarda-lo em casa pode não ser uma boa ideia, pois consome espaço e dependendo do produto oferece riscos a saúde das pessoas, portanto, a empresa que viabiliza o retorno desses bens tornar-se importante e eficaz na vida desse cliente.

Além do ponto de vista administrativo e estratégico, a empresa está submetida às leis, a Legislação ambiental contempla uma série de Resoluções CONAMA para óleos, pilhas, baterias e pneus, além de leis para garrafas e embalagens plásticas e a PNRS - Política Nacional de Resíduos Sólidos. Outro aspecto é o Código de Defesa do Consumidor (Lei 8.078, de 11 de setembro de 1990) que garante o direito do consumidor após a compra, seja de troca, reparo ou devolução.

Sendo assim, as empresas devem adequar suas operações para atender as exigências do governo e dos consumidores respaldados pela lei, que se insatisfeitos com 0 atendimento podem gerar passivos jurídicos ao negócio. A figura abaixo explicita a lógica desse processo. 
Figura 2 - Logística reversa adequada à lei.



\section{SISTEMA DE LOGÍSTICA REVERSA PóS-VENDA}

Fonte: Barreto (s/ano). Adaptada pelo autor.

\subsection{BENEFÍCIOS CORPORATIVOS AO ATUAR COM LOGÍSTICA REVERSA}

As empresas que pretendem perenizar seus negócios deverão adotar estratégias ambientais corporativas, que segundo Donato (2008) consiste em estabelecer ferramentas de coordenação e gestão, onde se encontram a Política de Desenvolvimento Logístico Sustentável e a Política de Gestão Ambiental. Dentre outras coisas, a Política de Desenvolvimento Logístico Sustentável, recomenda:

Substituir o óleo combustível pesado por fontes alternativas como gás natural nas caldeiras das unidades de geração de energia [...]; Utilizar combustíveis alternativos nos veículos de transporte, movimentação e distribuição [...]; Aplicar sistemas de reuso de água; Utilizar programas de aumento da vida útil dos pneus [...]; Implantar programas de reuso de 
óleo lubrificante; Implantar programas de destinação final de baterias inservíveis... (DONATO, 2008, p. 75)

Já a Política de Gestão Ambiental deve ser baseada no modelo preconizado pela ISSO 14001:2004 e de acordo com Donato:

A referida norma colocou a questão ambiental na agenda da alta administração das empresas e levou o tema meio ambiente aos funcionários de todos os níveis que, desta forma, forçou as empresas a investir nos processos com vistas à melhoria contínua e provocou um efeito-cascata na cadeia produtiva, com fornecedores de empresas certificadas sendo obrigados, por força do mercado, a também implantar o SGA. (DONATO, 2008, p. 84).

Ao atuar com logística reversa, seja por meio da Política de Desenvolvimento Logístico Sustentável ou por meio da Política de Gestão Ambiental, obtendo a certificação ISSO 14001:2004, as empresas efetivamente estarão contribuindo com a preservação do meio ambiente e merecidamente serão recompensadas por tais feios, pode-se dizer que desfrutarão de boa reputação junto à sociedade, consequente fidelização dos clientes e terão um diferencial para competir no mercado.

De acordo com Fabíola Ortiz (2013) da Associação O Eco, organização dedicada à cobertura de pautas sobre o meio ambiente, os consumidores estão mais interessados em produtos verdes:

$\mathrm{Na}$ disputa por conquistar o consumidor na hora de optar por qual produto escolher da prateleira, empresas multinacionais adotam novas estratégias ambientais e produtos cada vez mais verdes para atrair até os mais exigentes dos compradores. Muitos clientes se tornam fiéis a determinadas marcas e preferem pagar mais caro quando descobrem que determinado produto teve menos impacto ambiental. 
Os consumidores, cada vez mais exigentes e conscientes sobre questões ambientais, estão mais inclinados a comprar produtos verdes, oriundos de uma produção cada vez mais limpa e um processo logístico sustentável, pois é uma forma do consumidor firmar sua posição e contribuição com o meio ambiente. Sendo assim, a tendência será a fidelização desses clientes às empresas que praticam operações ecologicamente corretas.

Para Savitz e Weber (2007, apud Chaves, et tal, 2014, p. 6) "o histórico das empresas comprometidas com a sustentabilidade é plenamente compatível com o crescimento lucrativo no longo prazo, além de desfrutarem de melhor reputação". Ao operarem seus negócios com responsabilidade socioambiental, as empresas são percebidas por seus consumidores de forma muito positiva, pois comunicam preocupação não somente com o meio ambiente, mas precisamente com aqueles que desfrutam da natureza e seus recursos, ou seja, o ser humano, e de forma mais ampla não somente com a geração atual, mas também com a geração futura. A lucratividade no longo prazo e boa reputação são vantagens competitivas importantes para sustentabilidade do negócio.

\section{CONSIDERAÇÕES FINAIS}

Neste artigo identificou-se quão importante é a logística reversa para a sociedade e o meio ambiente, o tema é relevante para as empesas, governo, academia, agentes reguladores, órgãos internacionais e a sociedade civil como um todo. A humanidade está preocupada consigo mesma no presente e com as gerações futuras, consciente que deve consumir prudentemente e exigir das empresas produtos explorados, fabricados e processados, com vistas à preservação ambiental.

Verificou-se a necessidade de as empresas atuarem estrategicamente com a logística reversa e a maneira de se fazer isso, por meio de ferramentas e políticas de gestão apropriadas e que essa vocação é questão crucial para a sobrevivência do negócio. Ao utilizar a logística reversa de pós-venda a empresa criará um sistema logístico reverso regular e sistematizado para coletar os produtos devolvidos que não foram 
utilizados, e ao utilizar a logística de pós-consumo a empresas criará um sistema racional para reutilizar, reciclar e por fim descartar corretamente os produtos após sua vida útil. Desta maneira, além de cumprirem com as legislações ambientais, as organizações gozarão de melhor reputação e terão mais chances de fidelizar seus clientes.

Ao ponderar sobre a questão chave dessa pesquisa, constatou-se que as empresas têm plenas condições de implantar a logística reversa em suas operações, as motivações para isso são muitas, é uma questão de tratar o assunto com prioridade e adequar sua visão, missão e cultura organizacionais, se a alta direção da empresa estiver comprometida com a causa, naturalmente todo o corpo organizacional corresponderá às expectativas e os ganhos já mencionados certamente acontecerão.

Sugere-se para pesquisas futuras um aprofundamento no tema ciclo de vida dos produtos, que do ponto de vista comercial termina com a aquisição do bem pelo consumidor final, mas sob a perspectiva da logística reversa a responsabilidade empresarial é estendida até o descarte final desse produto.

\section{REFERÊNCIAS}

BARRETO, João Carlos. Logística Reversa e Sustentabilidade. Apostila. MBA em Logística e operações globais. Universidade Cândido Mendes. Rio de Janeiro.

CHAVES, Eduardo et al. Marketing verde como estratégia de sucesso da imagem corporativa. XI Simpósio de Excelência em Gestão e Tecnologia. Disponível em: https://www.aedb.br/seget/arquivos/artigos14/3220237.pdf. Acesso em: 19 jan. 2018

DONATO, Vitório. Logística Verde. Rio de Janeiro: Ed. Ciência Moderna, 2008. 276 p.

GIL, Antônio Carlos. Como elaborar projetos de pesquisa. 4. ed., São Paulo, Ed. Atlas 2002. $176 \mathrm{p}$. 
GUARNIERI, Patrícia; OLIVEIRA, Ivanir. A caracterização da logística reversa no ambiente empresarial em suas áreas de atuação: pós-venda e pós-consumo agregando valor econômico e legal. Revista tecnologia e humanismo. v.19, n.29, 2005. Disponível em: https://periodicos.utfpr.edu.br/rth/article/view/6372/4023. Acesso em: 20 dez. 2017

PRESIDÊNCIA DA REPÚBLICA. CASA CIVIL. Política Nacional de Resíduos Sólidos. Disponível em: http://www.planalto.gov.br/ccivil_03/_ato20072010/2010/lei/l12305.htm. Acesso em: 28 dez. 2017.

SOUZA, Sueli; FONSECA, Sérgio. Logística reversa: oportunidades para redução de custos em decorrência da evolução do fator ecológico. Revista Terceiro Setor. v.3, $\quad$ n.1, 2009. Disponível em: http://revistas.ung.br/index.php/3setor/article/viewFile/512/606. Acesso em: $18 \mathrm{dez}$. 2017

SUÇUARANA, Monik. Reciclagem. Infoescola (Disponível em: https://www.infoescola.com/ecologia/reciclagem/. Acesso em: 29 dez. 2017).

Enviado: Janeiro, 2019.

Aprovado: Agosto, 2019. 